\title{
The Relationship between Soft Skills, Self-Efficacy, and Career Development among Malaysian Generation
}

\author{
$\mathrm{Z}$ \\ Muhammad Asyraf Che Amat (Corresponding author) \\ Faculty of Educational Studies, Universiti Putra Malaysia, \\ Serdang, 43400, Selangor, Malaysia \\ Haziq Talhah \\ Faculty of Educational Studies, Universiti Putra Malaysia, \\ Serdang, 43400, Selangor, Malaysia
}

Received: Oct. 4, 2021 Accepted: Nov. 5, 2021 Online published: Nov. 22, 2021

doi:10.5296/ijhrs.v11i4S.19235 URL: https://doi.org/10.5296/ijhrs.v11i4S.19235

\begin{abstract}
Generation $\mathrm{Z}$ is the new generation that is entering the workforce in Malaysia. This generation will be the new major working people in Malaysia, which makes their career development an important topic. From the literature review, it was shown through many studies that Generation $\mathrm{Z}$ is aware of soft skills but lacks the practice of the said skills. However, they have remarkably high self-efficacy. Both soft skills and self-efficacy might influence Generation Z's career development. This leads to the aim of this study on identifying the relationship between soft skills, self-efficacy, and career development among Generation Z in Shah Alam, Selangor, Malaysia. This study involved a total of 384 Generation $\mathrm{Z}$ in Shah Alam. This research employed a quantitative correlational and descriptive research design. Soft Skill Questionnaire was used to identify the respondents' equipped soft skills and which soft skills they deemed important. Meanwhile, the self-efficacy variable was measured by using the General Self-Efficacy Scale. Lastly, career development was assessed using Career Development Assessment. Correlation analysis was used to test the relationship of variables involved. The results of the study showed that there was a relationship between soft skills, self-efficacy, and career development among Generation $\mathrm{Z}$ in Shah Alam. This study has implications for career counselling, counsellors, and Generation Z. Both soft skills and self-efficacy have influence on Generation Z's career
\end{abstract}


development massively.

Keywords: career development, Generation Z, soft skills, Malaysia, self-efficacy

\section{Introduction}

Due to a variety of factors, today's business environment is turning more complicated, ambiguous and competitive. All types of organizations consider human resources as their key asset, which plays a critical role in organizational performance and success (Schroeder, 2012). Most employers are likely to hire, retain, and promote employees who are dependable, resourceful, and ethical, have effective communication, willing to work and learn, and have a positive attitude. All these traits can be simplified into one term, which is soft skills. In addition, when it comes to skills in an occupation, the word self-efficacy plays a huge part in it. The essence of this study is focused and centralized around the terms soft skills and self-efficacy.

Generation Z, or also known as Gen Z, iGen, or centennials, refers to the generation that was born between 1997 and 2012, following millennials. Due to the frequency of technology usage and dependency, Generation $\mathrm{Z}$ is more technology-oriented than previous generations (Turner, 2015). However, the dependency on technology has made a difference in terms of lifestyle between previous generations and the current generation. People in Generation Z communicate with each other more in the virtual world (Turner, 2015). Social networks such as Facebook, Twitter, and Instagram are made as a platform for them to communicate. This is further bolstered by numerous apps created to promote online communication out there. Due to the dependency on technologies as compared to previous generations, this particular generation is said to be more impatient, instant-minded, lack any ambitions, are more prone to attention deficit disorders with a high dependency on technology, low attention span, individualistic, demanding, materialistic, and entitled (Agarwal \& Vaghela, 2019). This is further supported by Credo et al. (2018), whereby Generation Z is considered as an entitled and narcissistic generation in the workplace.

While many Generation $\mathrm{Z}$ consider themselves ready to join the workforce due to their open-mindedness and knowledge, employers see them as unprepared and lacking the necessary skills to flourish in the workplace (Jones, 2020). A major difference between Generation $\mathrm{Z}$ and the previous generations is that Generation $\mathrm{Z}$ comes with a great deal of information in their hands (Chillakuri \& Mahanandia, 2018). This leads the people from Generation $\mathrm{Z}$ to strongly believe that they have high self-efficacy in certain areas such as soft skills due to the information they have learned beforehand. The current generation might know about soft skills from information they stumbled upon somewhere in the vast digital world, but their application of those skills needs to be investigated.

\section{Literature Review and Hypotheses Development}

\subsection{The Importance of Soft Skills and Self-Efficacy towards Career Development among} Generation Z

Roselina (2009) in her article stated that the Ministry of Higher Education (MOHE) defines soft skills as incorporation of generic skills like communication, leadership, ethics, 
professional moral, critical thinking, problem-solving, teamwork, lifelong learning, information management, and entrepreneurship skills. As mentioned by Betts and Tang (2018), the application of soft skills helped to improve one's performance not just in academic but also in the workforce setting.

As time passes by, the workforce setting is changing due to technology, culture, beliefs, and ideals (Rami et al. 2018). However, all the variables above are influenced by one thing, humans themselves. Throughout history, humans are capable of influencing whatever they touch and mold it into whatever they want, be it good or bad. In the workplace setting, humans can achieve great things by flourishing the economic sector or destroying it all together. Therefore, by nurturing the two variables, namely soft skills and self-efficacy, it is hoped that the variables can improve career development and secure the generation's future.

Throughout the years, soft skills had been defined in various ways. The attitude of workers can make for a long and prosperous career development (Wahat, 2011). In the public health (PH) setting, it is not just about giving out medicine to the patients, it also involves how to approach the patients. As stated by Croitoru and Leiras (2019), a vaccination program would be further improved from health professionals who are capable of addressing their patients on the concern of its pros and cons. Having a group of health professionals with perspectives, multidisciplinary background, and skills would improve the services provided significantly.

In addition, the Covid-19 pandemic has brought deep-seating implications to the world (Mohd Rasdi et al., 2021). This especially includes the workplace setting throughout the globe. Employers are struggling to hold down their organizations and companies. The main concern in this aspect is employees. The capabilities of employees would determine the future of that organization or company.

\subsection{Previous Research on Soft Skills and Self-Efficacy towards Career Development}

Most research or studies on the soft skills topic were made from the vantage point of employers, while not many have been done on new employees' perception towards soft skills and their self-efficacy when it comes to their career development (Roslan et al., 2020). Furthermore, most research were carried out in America and Europe that have various work culture and learning environments than in Malaysia (Tan et al., 2021). Therefore, the worthiness of exploring and investigating Generation Z's perception towards soft skills and self-efficacy in a different angle locally is huge. In addition, the state of the new generation's career is at stake.

Fortunately, there are efforts and ways for the new generation to brush upon their soft skills. One of the ways is on how students can get themselves exposed to soft skills as suggested by Graduate Management News (2012). In the website, they can undergo soft skills assessment. Through the assessment, they can self-reflect on themselves about how they can improve in soft skills. The website has numerous actionable information for improvement, which includes articles, book summaries, coaching tips, resources, and videos for personal development. In addition, job benchmarking helps students to see how their personal profile is associated with the standards of different fields and job functions. Other than that, some 
scholars in the field of soft skills have created tools and systems to acquire soft skills. This can be corroborated by a study conducted by Rao (2014), which discovered that effective coordination among the faculty, students, industry, and leaders of educational institutions is a must in order to enhance employable skills among students.

The word self-efficacy stems from the Social Cognitive Theory. In terms of career, a newer theory was created, which is known as the Social Cognitive Career Theory (SCCT). The theory itself originally consisted of models of academic and career interest, choice, and performance (Lent et al., 2000). A fourth SCCT model was intended to understand the satisfaction and well-being in school and work settings (Lent \& Brown, 2008). The most recent SCCT model focuses on the self-management of a variety of adaptive career behaviours across the life span, which includes decision-making, job searching, and role transitioning (Lent \& Brown, 2013). The set of articles reviewed in this study centred around research on the interest and decision models, yet also included a number of articles on the newer satisfaction and self-management models. Given several limitations, this study is unable to summarise each model's primary predictions or the research testing methods. Instead, this paper referred to theory development articles (Lent et al., 1994), a recent overview of SCCT (Lent, 2013), meta-analyses of research on the interest (Sheu et al., 2010), and performance models ( Brown et al., 2011). Based on the theoretical explanations regarding soft skills and self-efficacy towards career development and the findings of previous studies, it is therefore the aim of this study to look into the relationship between soft skills, self-efficacy, and career development among Generation Z in Shah Alam. Specifically, the hypotheses of this study are as follows:

$\mathrm{H}_{1}$. There is a relationship between soft skills and career development.

$\mathrm{H}_{2}$. There is a relationship between soft skills and self-efficacy.

$\mathrm{H}_{3}$. There is a relationship between self-efficacy and career development.

\section{Materials and Methods}

\subsection{Research Instrument}

For the current study, questionnaires were the instruments given to the respondents via Google Form or email due to the pandemic. Through various research done on soft skills in the workplace and students' efficacy in soft skills by multiple authors, a set of questions that covered all the research problems for this study was created. The first questionnaire was adapted from Idrus (2013). This questionnaire consisted of three different sections. Section A comprised the demographics of the respondents. Section B consisted of questions related to the first research question, which focused on the importance of soft skills, while Section C contained questions related to the second research question that focused on how equipped the respondents were on soft skills in their workplace.

The second questionnaire was on the self-efficacy aspect of this research. The instrument used for self-efficacy was the General Self-Efficacy Scale. The scale was conceived to evaluate a general sense of perceived self-efficacy with the aim to predict how individuals handle daily events and the adaptation of an individual towards stressful events. The construct of Perceived Self-Efficacy echoes an optimistic self-belief (Schwarzer, 1992). This 
is the belief that one can perform a task that they have not done before or is challenging, or handle difficulties in various domains. There were ten questions in total and the respondents would have to answer from a scale of 1 to 4 ranging from 'Not true' to 'Exactly true'.

The third questionnaire was Career Development Assessment. It contained ten simple questions. The questionnaire included multiple choice answers whereby the respondents were required to choose from five available answers ranging from 'Strongly agree' to 'Strongly disagree'. Data collection was preceded by a pilot study only for the third instrument in order to evaluate the component of the third instrument as there was no initial reliability found for Career Development Assessment. The first two instruments had proven their own reliability and validity during the recent years. There were 30 samples selected for the pilot test from the population. The duration for the test was about 15 to 20 minutes by distributing to the participants using Google Form due to the Covid-19 pandemic. There were 12 female respondents and 28 male respondents with the age range from 18 to 24 years old in this pilot test.

The result of the pilot test was analysed to check for the reliability and validity of the third instrument of study. The reliability of career development was high, $r=.89$. As for the validity of the instrument, the researcher included two expert practitioners in the counselling field.

\subsection{Research Setting and Respondents}

For the study on the importance of soft skills in enhancing early career development among new employees, the respondents in this study comprised Generation $\mathrm{Z}$ who had work experience (interns included) from various companies and organizations. In addition, the population included Generation Z from Shah Alam, Selangor, Malaysia.

The samples were selected randomly from the population. Based on Krejcie and Morgan (1970), the samples in this research was 384. This was because the population of Shah Alam is 481,654 people as of this research period. As stated by the Malaysian Department of Statistics (2021), the number of Generation Z living in Shah Alam is more than 100,000. The sampling technique used for this study was simple random sampling, whereby every member of the population had the chance to be included as a respondent in this study.

\subsection{Characteristics of the Sample}

For this demographic section, the collected data were regarding gender, age, educational background, and duration of work experience. In this study, there were 193 males $(50.3 \%)$ and 191 females $(49.7 \%$ ) from the total of 384 respondents. The number of male respondents were more than female respondents. As for the age range, there were four categories of age range. In this study, there were $35(9.1 \%)$ from the age group of $18-19$ years old, $72(18.8 \%)$ were $20-21$ years old, $69(18 \%)$ were at the age of $22-23$ years old, and 208 (54.2\%) were at the age of 24 . This showed that the highest number of age range in this study was 24 years old. The educational background of the respondents could be grouped into five categories. There were $29(7.6 \%)$ respondents who only had SPM education level, 44 (11.5\%) were at the foundation level, 133 (34.6\%) respondents managed to make it through their diploma, 165 $(43 \%)$ of the respondents finished their degree level of education, and lastly, only $13(3.4 \%)$ 
respondents either managed to finish their master's degree or were currently pursuing their master depending on their age. This was because the researcher assumed that only a small percentage of Generation $\mathrm{Z}$ managed to finish a master's degree at such a young age. It is much more logical for a majority of Generation $\mathrm{Z}$ to finish their degree level education as shown in the study. The last aspect was the respondents' work experience, which was divided into two groups in this study. There were 226 (58.9\%) respondents who only had below two years of work experience, while $158(41.1 \%)$ had work experience of more than two years. From the results shown, most respondents only had below two years of work experience.

\section{Results and Discussion}

\subsection{Types of Soft Skills Demonstrated and Practiced by Generation Z in the Workplace}

In answering the first research question regarding the types of soft skills that were used and possessed by the respondents in their workplace, the scores were obtained through calculating the mean score for the items in the scale. The results revealed that teamwork had the highest mean score ( $\mathrm{M}=4.4440)$, which indicated that teamwork was used most by Generation $\mathrm{Z}$. The next highest mean score was leadership ( $M=4.3194)$, followed by ethics skills $(M=4.3125)$, lifelong learning skills $(M=4.2951)$, critical thinking skills $(M=4.2675)$, and lastly, communication skills $(\mathrm{M}=4.2382)$. In analyzing the mean scores, the interpretation was adapted from Landell (1997), whereby a mean of 1.00 to 2.33 signified low usage of strategy, 2.34 to 3.67 indicated average usage, and 3.68 to 5.00 suggested high usage. The result is summarized in Table 1 below.

Table 1. Descriptive Statistics ( $=384)$

\begin{tabular}{|c|c|c|c|c|c|}
\hline No. & Constructs & Minimum & Maximum & Mean & $S D$ \\
\hline 1 & $\mathrm{CO}$ & 2.23 & 5.00 & 4.2382 & .51829 \\
\hline 2 & CT & 2.55 & 5.00 & 4.2675 & .48836 \\
\hline 3 & LE & 2.73 & 5.00 & 4.3194 & .44176 \\
\hline 4 & ET & 2.60 & 5.00 & 4.3125 & .48888 \\
\hline 5 & LL & 2.33 & 5.00 & 4.2951 & .52607 \\
\hline 6 & TW & 2.75 & 5.00 & 4.4440 & .51014 \\
\hline 7 & Valid N (listwise) & & & & \\
\hline
\end{tabular}

Note. $\mathrm{CO}=$ Communication, $\mathrm{CT}=$ Critical thinking, $\mathrm{LE}=$ Leadership, $\mathrm{ET}=$ Ethics, $\mathrm{LL}=$ Lifelong learning, TW= Teamwork

In this section of the questionnaire, the respondents were required to answer which attributes of soft skills that they demonstrated in the workplace. There were six types of soft skills with their own attributes that the respondents had to answer. From calculating the mean of all attributes, the findings showed that the type of soft skills that Generation $\mathrm{Z}$ exhibited in their workplace was teamwork skill. Teamwork skills consisted of being able to build a good relationship with others, understand the benefit of working with others, and show consideration for the needs and feelings of others. Despite choosing communication skills as the most important, a majority of the respondents were more able in teamwork skills. The researcher deduced that teamwork skill was seen as the easiest skill to be demonstrated by the respondents. That aside, the researcher believed that the respondents should view teamwork 
skill as crucial as compared to just something easy. Nonetheless, this result contradicts with Stepanova et al. (2020) who stated that most employees were used to working alone, which made them omitting the benefit of working in a team.

\subsection{Relationship Between Soft Skills and Career Development}

Table 2. Correlation between soft skills and career development

\begin{tabular}{llll}
\hline Correlation between soft skills and career development & $\mathrm{R}$ & $p$ & Strength \\
\hline $\mathrm{N}=384$ & $0.423^{* *}$ & .000 & Moderate \\
\hline
\end{tabular}

A Spearman's rank-order correlation was run to determine the relationship between soft skills and career development among Generation z. A statistically significant positive correlation between soft skills and career development was found, $\mathrm{r}(384)=.423, \mathrm{p}<.001$, indicating that Generation $\mathrm{Z}$ who possessed soft skills had a moderate positive correlation with career development. Therefore, hypothesis 1 is accepted.

It can be seen that there was a moderate relationship between soft skills and career development. Li (2021) in his article stated that rapid globalization and technology had made the society call for higher requirements concerning soft skills. In addition, lifelong learning and holistic view in education were implemented by Chinese societies influenced by Western theories on career education. The aim of this change is to improve the career development of youth in China. This proves that there is a relationship between soft skills and career development. In one of the items in the Career Development Assessment questionnaire used in this study, a high percentage of respondents agreed that soft skills helped in strengthening their career development. Career development does not only mean getting more salary or getting into a higher position in an occupation. It revolves around an individual as an employee to enhance his/her personality, skills, and values in an occupation.

\subsection{Relationship between Soft Skills and Self-Efficacy}

Table 3. Correlation between soft skills and self-efficacy

\begin{tabular}{lccc}
\hline Correlation between soft skills and self-efficacy & $\mathrm{R}$ & $p$ & Strength \\
\hline $\mathrm{N}=384$ & $0.518^{* *}$ & .000 & Moderate \\
\hline
\end{tabular}

A Spearman's rank-order correlation was run to determine the relationship between soft skills and self-efficacy among Generation Z. A statistically significant positive correlation between soft skills and self-efficacy was found, $\mathrm{r}(384)=.518, \mathrm{p}<.001$, indicating that Generation $\mathrm{Z}$ who acquired soft skills had a moderate positive correlation with self-efficacy. Hypothesis 2 is thus accepted.

From the finding of the study, it is shown that there was a moderate relationship between soft skills and self-efficacy. One main point why the researcher chose self-efficacy as another variable was because its connection to soft skills. Self-efficacy is one's confidence in doing a task given or in this case having a skill to complete something. In a research by Trisnaningati and Sinambela (2021), it revealed that the capability of someone in a public speaking 
competition depended on his/her self-efficacy. Therefore, it begged for the question on which one comes first: soft skills or self-efficacy. From the researcher's point of view, both are equally important and might change roles with each other. An individual's soft skills might be better with high self-efficacy and an individual's self-efficacy can be enhanced by practising soft skills.

\subsection{Relationship Between Self-Efficacy and Career Development}

Table 4. Correlation between self-efficacy and career development

\begin{tabular}{lccc}
\hline Correlation between self-efficacy and career development & $\mathrm{R}$ & $p$ & Strength \\
\hline $\mathrm{N}=384$ & $0.539^{* *}$ & .000 & Moderate \\
\hline
\end{tabular}

A Spearman's rank-order correlation was run to determine the relationship between soft skills and self-efficacy among Generation Z. A statistically significant positive correlation between self-efficacy and career development was found $\mathrm{r}(384)=.539, \mathrm{p}<.001$, indicating that Generation $\mathrm{Z}$ who had self-efficacy had a moderate positive correlation with career development. Therefore, hypothesis 3 is accepted.

There was a moderate relationship between self-efficacy and career development from the findings of this study. Being able to have high self-efficacy will make an individual progress faster than those who have low self-efficacy in a task, by being willing to take charge and do it first before others. Moreover, in one of the items in the Career Development Assessment used in this study, a majority of respondents agreed that self-efficacy helped in strengthening their career development. However, the relationship between self-efficacy and career development could also be seen at the start of a career path. Abe et al. (2021) stated in their study that self-efficacy predicted career development in a sense that by having high self-efficacy in certain jobs, individuals will surely go on the same career path in the future.

\section{Implications}

\subsection{Pedagogical Implications}

From the findings of this study, three pedagogical implications were suggested, namely (1) towards career counselling, (2) towards counsellors, and (3) towards Generation Z.

\subsection{Career Counselling}

Based on the result of this study, it showed that soft skills and self-efficacy had a relationship with career development. This should make career counsellors become more aware on conducting career counselling using soft skills at counselling centers or in counselling programs. The researcher hopes that this study can be a stepping stone or catalyst in improving the process for career counselling. All types of soft skills are positive and proven to be helpful in changing people for the better in an individual's career path.

\subsection{Counsellors}

From the findings, the researcher also hopes that counsellors would use soft skills in their session. This can be done by putting an emphasis on soft skills to the clients and explore the 
clients through each part of the soft skills, such as communication, leadership, and teamwork skills. Aside from that, soft skills can be further modified and upgraded so that it truly becomes a tool or theory suitable for counselling. By modernizing ways in counselling and counsellors' way of thinking, it will bring about a better outcome for clients in this era who are inflicted by issues easily from their phone. Counsellors should also improve themselves based on the soft skill attributes listed and become better in their career path as a counsellor.

\subsection{Generation Z}

In the problem statement of this study, it was indicated that employers were having difficulties with employees from Generation $\mathrm{Z}$ due to them being more reliant on screen and technology while at the same time lacking communication skills and teamwork attributes. However, from the findings, it was shown that the result was the opposite of the problem statement. The results revealed that Generation $\mathrm{Z}$ had a positive perception of soft skills and the practice of soft skills in their workplace, whereby the most frequent skill they practised was teamwork skills.

\section{Conclusion}

The career development of Generation $\mathrm{Z}$ has bigger implications rather than just an improvement towards their career. Generation $\mathrm{Z}$ will be the ones to lead the workforce of this country. Not to forget the fact that the world has changed immensely due to the Covid-19 pandemic. By emphasising more on their career development, the future of this country's workforce would flourish and prosper for the better. Counsellors must be cognizant of what factors contribute towards the career development of this particular generation and the reasons behind them so that they can be helped should they face any problems in the future. Enhancing their soft skills and self-efficacy through career counselling specifically may help them achieve more in career development. It is hoped that the findings of this study will provide counsellors with a better way to understand Generation Z, especially new employees within that generation, in order to improve their career development.

\section{References}

Agarwal, H., \& Vaghela, M. P. S. (2019). Work Values of Gen Z: Bridging the Gap to the Next Generation.

Betts, J. R., \& Tang, Y. E. (2018). The effects of charter schools on student achievement. In School Choice at the Crossroads (pp. 69-91). Routledge. https://doi.org/10.4324/9781351213318-5

Chillakuri, B., \& Mahanandia, R. (2018). Generation Z Entering The Workforce: The Need For Sustainable Strategies in Maximizing Their Talent. Human Resource Management International Digest. https://doi.org/10.1108/HRMID-01-2018-0006

Idrus, H. (2013). Integration of soft skills in the teaching of technical courses: an exploratory study of a private university (Doctoral dissertation, Universiti Teknologi MARA).

Jones, W. (2020). The Influence of Emotional Intelligence Training on College Student 
Employee Workforce Readiness.

Lent, R. W., Brown, S. D., \& Hackett, G. (2000). Contextual supports and barriers to career choice: a social cognitive analysis. Journal of Counseling Psychology, 47(1), 36-49. https://doi.org/10.1037/0022-0167.47.1.36

Lent, R. W., \& Brown, S. D. (2008). Social cognitive career theory and subjective well-being in the context of work. Journal of Career Assessment, 16(1), 6-21. https://doi.org/10.1177/1069072707305769

Lent, R. W., \& Brown, S. D. (2013). Social cognitive model of career self-management: toward a unifying view of adaptive career behavior across the life span. Journal of counseling psychology, 60(4), 557-568. https://doi.org/10.1037/a0033446

Li, Y. (2021). Career Development and Life Planning Education from a Holistic Perspective. Teachers magazine, 70-80.

Mohd, R. R., Zaremohzzabieh, Z., \& Ahrari, S. (2021). Financial Insecurity During the COVID-19 Pandemic: Spillover Effects on Burnout-Disengagement Relationships and Performance of Employees Who Moonlight. Frontiers in Psychology, 12, 1-14. https://doi.org/10.3389/fpsyg.2021.610138

Rao, M. S. (2014). Enhancing employability in engineering and management students through soft skills. Industrial and Commercial Training, 46(1), 42-48. https://doi.org/10.1108/ICT-04-2013-0023

Roslan, S., Ping, W. S., Sulaiman, T., Jalil, H. A., \& Siaw, Y. L. (2020). Psychometric properties of graduate employability instrument among malaysian higher education institution students. Universal Journal of Educational Research, 8(1A), 164-178. https://doi.org/10.13189/ujer.2020.081321

Schroeder, H. (2012). The importance of human resource management in strategic sustainability: an art and science perspective. Journal of Environmental Sustainability, 2(2), 75-82. https://doi.org/10.14448/jes.02.0004

Schwarzer, R. (1992). Self-Efficacy: Thought Control of Action. Taylor \& Francis.

Sheu, H. B., Lent, R. W., Brown, S. D., Miller, M. J., Hennessy, K. D., \& Duffy, R. D. (2010). Testing the choice model of social cognitive career theory across holland themes: a meta-analytic path analysis. Journal of Vocational Behavior, 76(2), 252-264. https://doi.org/10.1016/j.jvb.2009.10.015

Stepanova, E., Rozhkova, A. V., \& Grishina, I. I. (2020). Team Building as a Method of Teaching Students and Group Cohesion. In 20th European Conference on Research Methodology for Business and Management Studies: ECRM 2020. Academic Conferences and publishing limited.

Tan, C. Y., Abdullah, A. G. K., \& Ali, A. J. (2021). Soft skill integration for inspiring critical employability skills in private higher education. Eurasian Journal of Educational Research, 
92, 23-39. https://doi.org/10.14689/ejer.2021.92.2

Trisnaningati, Z. R., \& Sinambela, F. C. (2021). Self-efficacy, Emotional Regulation, Communication Competence and Public Speaking Anxiety towards Students. Proceedings of the International Conference on Psychological Studies (ICPSYCHE 2020). https://doi.org/10.2991/assehr.k.210423.010

Turner, A. (2015). Generation Z: technology and social interest. The Journal of Individual Psychology, 71(2), 103-113. https://doi.org/10.1353/jip.2015.0021

Tyszko, J. A., \& Sheets, R. G. (2021). The Agility Imperative: The Future of Work and Business-Higher Education Partnerships in the Great Skills Gap. Stanford University Press. https://doi.org/10.1515/9781503628076-029

Wahat, N. W. A. (2011). Towards Developing a Theoretical Framework on Career Success of People with Disabilities. Asian Social Science, 7(3), 62-70. https://doi.org/10.5539/ass.v7n3p62

\section{Copyright Disclaimer}

Copyright for this article is retained by the author(s), with first publication rights granted to the journal.

This is an open-access article distributed under the terms and conditions of the Creative Commons Attribution license (http://creativecommons.org/licenses/by/4.0/). 